\title{
A via crucis da juventude brasileira: educação e metáfora a partir da antropologia do imaginário
}

The via crucis of the brazilian youth: education and metaphor by imaginary anthropology's point of view

\author{
Elza Kioko Nakayama Nenoki do Couto \\ UFG \\ kiokoelza@gmail.com
}

\section{Lorena Araújo de Oliveira Borges \\ UnB / Capes \\ lorena.aoborges@gmail.com}

\begin{abstract}
RESUMO: Tomando-se como ponto de partida a encenação da via crucis realizada durante a Jornada Mundial da Juventude, em 2013, no Rio de Janeiro, esse artigo tem o objetivo de descrever e analisar o uso do processo metafórico como um exercício de ensino e aprendizagem tanto dos jovens brasileiros quanto da sociedade como um todo. Para tanto, foram observadas, primeiro, as imagens resultantes da faculdade de imaginação; depois, as estruturas que tais imagens organizam. O principal intuito foi o de compreender as reformas da chamada Igreja Nova, ou seja, desvelar o imaginário da construção do conhecimento religioso em seu discurso performático.
\end{abstract}

Palavras-chave: Imaginação e imaginário; Ensino e aprendizagem; Metáfora; Via crucis.

ABSTRACT: Taking as starting point the via crucis' staging held during the World Youth Day 2013, in Rio de Janeiro, this article aims to describe and analyze the use of metaphorical process as a teaching exercise and learning for the youngsters and the society as a whole. Thus, we observed, first, the images resulting from the imagination faculty; then the structures that organize such images. The main aim was to understand the reforms called New Church, that is, to reveal the imaginary construction of religious knowledge in his performative discourse.

Keywords: Imagination and imaginary; Teaching and learning; Metaphors; Via crucis. 


\section{A encenação da via crucis}

A Jornada Mundial da Juventude é um grande evento itinerante promovido pela Igreja Católica Apostólica Romana com o objetivo de transmitir os ensinamentos cristãos às gerações mais jovens. Em 2013, ela teve a cidade do Rio de Janeiro como palco e ganhou amplo destaque nas mídias nacionais devido à vinda do Papa Francisco pela primeira vez ao Brasil. O desfile da via crucis foi o ponto culminante dessa Jornada e levou quase um milhão de fiéis à praia de Copacabana, no início da noite de sexta-feira de 23 de agosto. A grande encenação foi o resultado da imaginação de um grupo de pessoas e foi precedida por estudos, pesquisas, organogramas, assim como por inúmeras discussões e ensaios no plano da realização. É, simplesmente, o resultado concreto, visível, operável por mais de 300 atores que se deleitaram em vivenciar a grandeza das cenas vistas e reconhecidas por milhões de pessoas in loco ou na TV, como um fato valioso da imaginação.

As quatorze estações reproduziram o trajeto percorrido por Jesus na cidade de Jerusalém. O trajeto, entretanto, foi configurado de acordo com a imaginação do brasileiro. Assim, a (re)encenação desse ritual ocorreu num percurso de 900 metros da Avenida Atlântica, entre a Pedra do Arpoador e a Escadaria Selarón, na Lapa, sendo finalizada no palco central, de onde o Papa Francisco assistia à celebração. A descrição que faremos dessa representação, a seguir, é fruto de duas fontes distintas: 1) um documento liberado pela organização da própria Jornada, com todas as falas e detalhes da encenação; 2) a transmissão ao vivo do evento, que posteriormente foi disponibilizada em canais da internet.

Revista Texto Poético | ISSN: 1808-5385 | Vol. 18 (10 sem-2015) - p. 186 
Faz-se necessário destacar que a via crucis da Jornada de 2013 foi reproduzida de duas formas. Primeiro, no plano mais alto, onde Cristo é configurado como a figura bíblica. Depois, no cenário criado mais abaixo, com jovens da atualidade colocando-se metaforicamente na mesma posição de sofrimento de Cristo. No primeiro plano estava o ensinamento bíblico (por meio da figura de Cristo); no segundo, a metáfora que atualiza o sofrimento de Cristo para os dias atuais. A análise que desenvolveremos a seguir vai se restringir ao segundo plano.

\section{Primeira Estação}

O tema é o julgamento de Jesus e sua condenação. A estilística do imaginário optou por tratar do polo oposto: não há a defesa de Cristo, mas referência a jovens inocentes que "todos os dias são condenados à morte pela pobreza, pela violência e por todo tipo de consequências do pecado". Destaca-se, portanto, outra fonte de morte: a causada pelas consequências do pecado, pela ausência da presença e ação do governo em geral.

\section{Segunda Estação}

Jesus carrega a cruz. A meditação focaliza o momento em que Jesus toma a cruz nos ombros tendo como perspectiva auxiliar o jovem convertido a se regenerar. No cenário, tem-se a presença de atores vestidos de preto, carregando dezenas de cruzes aos braços. Assim que a cruz de madeira chega em frente à estação, as cruzes são lançadas ao chão, representando o processo de conversão. "Fui convertido pelo teu divino 
Coração. Tomaste sobre os ombros minhas dores e misérias", dizia o texto. A aprendizagem está na reflexão.

\section{Terceira Estação}

Jesus cai pela primeira vez. Vê-se um jovem pintado de branco levando a cruz, no alto, com um dos joelhos encostado no chão. Os elementos cênicos lembram a fé do povo brasileiro: as filhas de Maria, os romeiros e os peregrinos. A meditação é feita por um jovem voluntário que trabalha numa comunidade de recuperação. Aprende-se a ajudar os outros do ponto de vista comportamental. Aqui é evocada a prece do "voluntário de uma comunidade de recuperação" que quer ser o bom samaritano que "para além dos discursos, tem coragem de levantar quem está caído à beira do caminho e cuidar de suas feridas".

\section{Quarta Estação}

Jesus encontra a sua mãe aflita. Além da atriz que representa a Virgem Maria, mulheres com seus filhos pequenos compõem o cenário. A meditação afirma: "Queremos proclamar com tua mãe: o Senhor fez em mim grandes coisas. Derruba do trono os arrogantes e eleva os humildes. Manifesta o poder de seu braço e nos sustenta pelo caminho". Há referência, ainda, às dores das mães que sentem o sofrimento de seus filhos. Uma jovem grávida falou em nome das mães. Além de retratar as dores e sofrimentos que as mães sentem por seus filhos, teve mensagens sobre a valorização e defesa da vida. Aprende-se com a mãe e com outros, jovens e filhos, o valor da mãe. 


\section{Quinta Estação}

O palco dessa estação tem um relicário no alto da escadaria. Dentro dele está a imagem de Jesus carregando a cruz e Simão estendendo-lhe a mão. Os elementos escolhidos levam a uma visão celestial e fazem referência à arte sacra popular brasileira, com o rebuscamento do barroco de Aleijadinho. As meditações foram feitas por um jovem chamado ao sacerdócio e reflete o desejo de se configurar como o Cristo Bom Pastor. "Livra-me da tentação dos primeiros lugares e ensina-me a ser um bom pastor", pede ele. Aqui, os "seminaristas" chamados ao sacerdócio também estão presentes com as suas orações e preocupações. As lições se dirigem, nessa estação, aos futuros padres.

\section{Sexta Estação}

O palco foi inspirado no altar do oratório do convento das Pequenas Irmãs de Jesus, em Jerusalém. No simulacro dele, mulheres representam Verônica, a mulher que teve a coragem e a ousadia de secar o rosto de Jesus no meio de sua agonia até o Calvário. Essa estação reflete a luta em defesa pela vida. Há o aprendizado contra o aborto e o pedido de alguém que, consagrado ao "serviço do irmão", pede forças porque encontra "nas vias-sacras da vida tantas vítimas de uma "cultura de morte".

\section{Sétima Estação}

Jesus cai pela segunda vez. Há pessoas vestidas com macacões, representando operários, metalúrgicos, mecânicos e mineiros. No palco, um contêiner faz referência ao trabalho pesado da construção 
civil. De dentro dele sai uma estátua viva que representa Cristo caído de joelhos sob sua cruz. Dessa vez, Jesus está no chão, caído, pintado na cor marrom, representando o sofrimento terreno. A meditação leva os jovens a contemplar o papel do namoro no início da construção da família. "Dá-nos a sabedoria de começar a construção pelos fundamentos e não pelo telhado. Ensina-nos que cada escolha exige renúncias", diz o casal de namorados que representam aqueles que pretendem "construir uma família".

\section{Oitava Estação}

Jesus consola as mulheres de Jerusalém. Há nesta encenação 15 mulheres que representam a mulher contemporânea em busca de seu papel na sociedade atual. Vestidas como médicas, enfermeiras, professoras, executivas, domésticas, jornalistas, todas carregam uma muda que foi plantada na escadaria do palco assim que a cruz de madeira chegou à estação. A meditação une o sacrifício de Cristo à vocação da mulher, lembrando o sofrimento das mulheres.

\section{Nona Estação}

Jesus cai pela terceira vez. Jovens motoboys e cadeirantes sobem até o palco dessa estação enquanto um ator, representando Cristo carregando a cruz de madeira, cai pela terceira vez. Ele reaparece, novamente no alto, iluminado por uma luz branca. Essa estação é dedicada ao cadeirante e é ele que faz a leitura da meditação dessa estação enfatizando a importância de Jesus na vida dos cristãos. "Apenas quem encontra a Verdade, para além dos limites do corpo, fica verdadeiramente de pé", aponta.

Revista Texto Poético | ISSN: 1808-5385 | Vol. 18 (10 sem-2015) - p. 190 


\section{Décima Estação}

Jesus é despojado de suas vestes. Há uma reprodução icônica da Basílica da Ressurreição de Jerusalém. A rampa sinuosa do palco estação, coberta com um tapete vermelho, criou uma perspectiva rumo ao céu. Um ator representando Cristo flagelado sobe a rampa sozinho e, no topo dela, abre os braços, representando uma cruz. "Olhando para o teu despojamento total no caminho da cruz eu peço em nome da minha geração: que a tua graça nos ensine os caminhos para evangelizar o 'continente digital'", aponta a meditação. Fala, ainda, sobre os jovens conectados pela internet, e lembra a formação das redes sociais. Após referir-se à inclusão digital, pede enfaticamente: "Que a tua graça nos ensine os caminhos para evangelizar o 'continente digital' e nos deixar atentos à possível dependência ou confusão entre o real e o virtual”.

\section{Décima Primeira Estação}

Jesus é pregado na cruz. Há uma referência aos carcerários, ou seja, são lembrados os milhões de jovens presidiários. Os degraus do palco da Estação levam a um muro grande e imponente. Vestidos de terno e gravata, homens angustiados se ajoelham em oração. Por uma porta giratória, no meio do muro, Cristo aparece em cena, com o corpo pintado na mesma textura do muro, mas logo desaparece. A meditação é feita por um jovem da pastoral carcerária e fala sobre aqueles que perderam a liberdade, mostrando que os sofrimentos de Cristo libertam a todos de suas prisões. Também afirma que Jesus ama tanto os justos quanto os pecadores.

Revista Texto Poético | ISSN: 1808-5385 | Vol. 18 (10 sem-2015) - p. 191 


\section{Décima Segunda Estação}

Jesus morre na cruz. O palco também traz um muro grande com muitas janelas e uma porta, que são abertas durante a encenação. Os atores caem de joelhos, com as mãos no chão, quando a porta é aberta e uma luz forte emana de lá de dentro. Aqui há pessoas vestidas de enfermeiros, carregando macas e cadeiras de rodas. A cena da estação faz referência às pessoas com doenças terminais e tem elementos que indicam a luz de Cristo, refletindo a ideia de morte. A meditação dessa estação fala sobre os jovens que estão próximos da morte, levando os peregrinos a unirem suas dores as dores de Cristo.

\section{Décima Terceira Estação}

Jesus é descido da cruz. No centro do palco, duas figuras brancas se apresentam como a Pietá, de Michelangelo. As figuras são coloridas por luzes intensas, vermelha e amarela. Do alto, caem tecidos vermelhos com bolas na extremidade mais próxima do palco, se assemelhando ao sangue que escorre. Antes da meditação, as figuras brancas são retiradas para o fundo do palco. Essa estação é dedicada ao jovem com deficiência auditiva. O texto é sinalizado em Libras e traduzido por uma jovem: "Existem momentos em que o silêncio e a contemplação falam muito mais".

\section{Décima Quarta Estação}

Jesus é sepultado. A Cruz Peregrina é posta no palco central de Copacabana, onde se encontrava o Papa Francisco, além de voluntários, artistas e músicos. A quantidade de pessoas simboliza o 
mundo inteiro. A meditação é lida por jovens dos cinco continentes, a fim de fazerem preces pela evangelização em suas regiões, destacando o que é mais urgente em cada país. A via crucis é encerrada pelo Papa.

\section{Do símbolo à metáfora}

Ao estudar eventos e grandes espetáculos no Prefácio e na Introdução de sua obra Le décor mythique de La Chartreuse de Parme, na terceira edição francesa, Durand (1983) se preocupa em definir o que chama de "estrutura" e recomenda para que não se faça a confusão com o termo "forma". Para esse autor,“[u]ma estrutura é um conjunto dinâmico; isto é, um sistema de forças ou de imagens antagônicas" (DURAND, 1983, p. 05), sistema que, por sua vez, compreende "constelações de imagens coerentes e estáveis chamadas arquétipos". Acrescenta, ainda, que não se pode conceber um pensamento sem imagens, e estas, ao se organizarem ou se "polarizarem, criam formalmente, o que se chama estilística" (DURAND, 1983, p. 06).

É por meio da estilística que as diversas formas, sejam literárias, musicais, dramáticas ou plásticas, conseguem ser entendidas imediata e facilmente pelo indivíduo. Se a música e os espetáculos evidenciam logo o seu sentido, pois têm um suporte semântico ${ }^{16} \mathrm{e}$ implicam processos "instaurativos", o mesmo não acontece com a língua. Esta exige um processo de decodificação e, exatamente por isso, torna-se menos direta e rápida. É por isso que os romances

${ }^{16}$ Durand adota a distinção estabelecida por Saussure acerca desses dois conceitos: a verdade da semântica é de segunda mão, pois pede mediatização ou representatividade de algo que está fora de seu processo.

Revista Texto Poético | ISSN: 1808-5385 | Vol. 18 (10 sem-2015) - p. 193 
demandam um longo percurso de construção dramática. A relação com o mosteiro, em $O$ Vermelho e o Negro, por exemplo, é o dispositivo espacial escolhido por Stendhal para situar a história de amor de Madame de Rênal e Julien Sorel, história que, por ser transmitida apenas pelo código linguístico, implica a criação de textos em várias páginas e capítulos para comover seu leitor.

Nesse sentido, o primeiro dado importante a se considerar no exame da estética de obras espetaculares, como as que ocorreram durante a Jornada Mundial da Juventude no Brasil, é a observação de como elas mostram, propagam e expandem as formas do mítico. Durand, repetindo Lévi Strauss, esclarece que o mítico é, dentre as várias formas do discurso, a que é menos modificada em seu processo de transmissão. Tal fato acontece porque o mito, assim como boa parte da literatura popular ou infantil, se liga mais ao estado ou à natureza da alma humana e menos à do mundo. Além disso, podem ser facilmente reproduzidos ou focalizados no plano de sua compreensão e propagação.

O segundo dado importante para a implantação e difusão de obras espetaculares é distinguir, com mais clareza, os termos imaginação e imaginário. A imaginação é a atividade ou a faculdade de criar, reconhecer, assimilar, memorizar e reproduzir imagens reais ou fantásticas. Constitui, por exemplo, a capacidade de planejar ou promover eventos, criar cenários, grandes cenas e sensações, de tal modo fascinantes ou sensibilizadoras que podem marcar a consciência do espectador, estabelecendo-se como algo ao qual ele pertence, não apenas ilusoriamente, mas efetivamente. Neste caso, os apelos à imaginação são fortes, uma vez que é possível ao espectador deixar de ser ilusoriamente participante ou apenas observador para se sentir integrado ao tema em 
questão. Tal observação nos faz atentar, como sugere Durand (1993), para o fato de que

[t]odo simbolismo é, pois, uma espécie de gnose, isto é, um processo de mediação por meio de um conhecimento concreto e experimental. Como uma determinada gnose, o símbolo é um "reconhecimento beatificante" um "conhecimento salvador" que, previamente, não tem necessidade de um intermediário social, isto é, sacramental e eclesiástico (DURAND, 1993, p. 31).

A partir dessa perspectiva, faz-se necessário retomar a questão do simbolismo a fim de esclarecer que todo símbolo remete para algo, mas não se reduz a uma única coisa. Ao contrário, liga-se ao sentido espiritual do instinto que, mostrando-se naturalmente ambíguo, torna-se o que Jung classificou como "arquétipo". Durand complementa essa classificação apontando que

[o] arquétipo é, pois, uma forma dinâmica, uma estrutura organizadora das imagens, mas que transvaza sempre as concreções individuais, biográficas, regionais e sociais, da formação das imagens (DURAND, 1993, p. 56).

O simbolismo torna-se, assim, um processo que busca implantar um equilíbrio biológico, psíquico e sociológico, pois, afinal, é esta a função da imaginação. Esse, provavelmente, também foi o objetivo da Jornada Mundial da Juventude na reencenação da via crucis de Jesus até o Calvário.

Se na antropologia do imaginário a imagem funciona como símbolo geral - entendido como a conjugação de um sentido e de uma imagem, ou seja, de um aspecto vivido (no qual se manifesta o sentido) e de um componente espacial (no qual se manifesta a imagem) -, pode-se dizer que ela é formada de um quadro, onde a 
imagem se revela símbolo porque, mantendo suas raízes tanto no sensível quanto no inteligível, recebe igualmente as significações das experiências vividas na subjetividade e na objetividade do cotidiano. Dessa maneira, a imagem se organiza de forma emblemática: distancia-se, ao mesmo tempo, do particular e do universal, mas com o objetivo de articular os dois de modo a fazer o universal ser intuído no particular e o global ser formado do local. Essa articulação é a responsável pela transformação da imagem/signo em imagem/símbolo. A expressão metafórica, por sua vez, surge quando a imagem/signo assume a natureza de imagem/símbolo, na qual o particular se estrutura com o geral e possibilita a transcendência de um sentido local para um sentido global, ou vice-versa.

No plano do simbolismo, Strôngoli aponta que

a metáfora não diz, portanto, respeito à realidade especifica de uma situação ou pessoa; confirma apenas uma realidade universal: a da humanidade ou do mundo em geral, ou melhor, dos arquétipos. [...] A metáfora, participando da natureza do símbolo pela atividade de substituição possibilita, assim, ao indivíduo a liberdade de aceitá-la como imagem metafórica ou apenas como signo vazio de seu simbolismo. Entretanto, se há liberdade para escolha, não há liberdade para se chegar ao insight: o indivíduo necessita aderir à imagem/símbolo para esta iluminar a compreensão da nova realidade ou direção semântica (STRÔNGOLI, 2002, p. 199-200).

Assim, do ponto de vista da antropologia durandiana, a imagem se destaca por sua transcendência e é sob este aspecto que deve ser relacionada à metáfora, afinal a transcendência está no cerne de sua constituição. 
A metáfora, nesse artigo, não está circunscrita apenas à percepção e experiência de uma boa parte do mundo, como afirma Lakoff \& Johnson (2002, p. 358). Acrescenta-se a isso que as metáforas são faculdades imaginativo-passional do sujeito. Afinal, se a linguagem existe para falarmos do mundo, a metáfora é um recurso que usamos para aumentar nosso poder referencial, para aumentar nossa capacidade de falar do mundo, requisitando na sua criação as potencialidades semânticas do símbolo, pois só o símbolo, enraizando-se na profundidade da vida e do ser, é que se reveste de poder e de eficácia para representar, essencialmente, o ser e o existir do sujeito pela linguagem não só da poesia, mas também de nossa linguagem e atos cotidianos.

Nessa perspectiva, é necessário focalizar não só a natureza da imaginação, mas também a do imaginário. O imaginário é o modo particular de o indivíduo operacionalizar a faculdade da imaginação, de pô-la em prática, articulando e configurando imagens nos dois polos. Ele se manifesta diversamente de um indivíduo para outro ou mesmo no próprio indivíduo, devido, como afirma Durand (1989), às diferenças nascidas dos imperativos de seu biologismo, de seu psiquismo e de suas pulsões, bem como das intimações de seu meio social.

Voltando à encenação da via crucis durante a Jornada Mundial da Juventude/2013, observa-se que a imaginação faculta presentificar imagens que se revestem de dois polos, o bem e o mal, a vida e a morte; mas é o imaginário que constrói a interação tensional nascida de suas diferenças e similitudes, dando-lhes contornos e dimensões semânticos específicos. Assim, diante dessas imagens, o indivíduo vai articular outras em função de seus imperativos subjetivos (idade, gênero, temperamento e pulsões) e de 
suas intimações objetivas (função e contexto sociais). As funções e contexto sociais de um indivíduo podem motivá-lo, por exemplo, a articular ao bem imagens da não-violência, da paz, do amor e da fé que, confrontadas com as articuladas por outro indivíduo, em função ou contexto social diferente, evidenciam configurações que certamente darão à imagem de violência, injustiça, agressividade criando, do ponto de vista da subjetividade, sentimentos diversos que podem conotar pesar ou revolta, satisfação ou orgulho, e revelar acentos positivos ou negativos para um ou outro polo semântico.

E se aqui podemos aproximar metáfora de imaginação e imaginário é porque na configuração desses processos há uma forma particular de configuração que, escapando de toda coação lógica e objetivante, dela se libera para instaurar, num nível mais alto, o poder figurador dos símbolos e das analogias. A metáfora, conforme aponta Durand (1989, p. 285), é o processo de expressão do imaginário, "esse poder que tem o espírito, cada vez que pensa, de renovar a terminologia”.

Cabe a nós, agora, estudar como a imaginação se programa para tal função, arregimentando imagens e símbolos para possibilitar que, em seguida, o imaginário se manifeste para pôr ordem no caos da interação dos vários símbolos e estruturas, pois, como já sabemos, se a imaginação é uma faculdade, o imaginário é o responsável pela elaboração de suas estruturas, aquelas que atingem significativamente o espectador.

\section{A via crucis: da imaginação ao imaginário}

A Cruz Peregrina, o principal símbolo da Jornada, começou a ser construída na semana santa de 1983 e foi finalizada para a 
semana santa do ano seguinte. Foi doada por João Paulo II para o Centro Juvenil Internacional de São Lourenço, Roma. Esta cruz inaugurou a estilística do imaginário dessa via crucis: dar voz à juventude e ajudá-la em seu desenvolvimento. O tamanho dela $(3,80 \mathrm{~m})$ deu força ao sentido de seu arquétipo, a saber, o de mal do mundo. Este é simbolizado em dois espaços paralelos, mas diferentes: o situado mais alto possibilita o trajeto sofrido de Jesus na antiguidade; o situado mais próximo ao rés do chão da avenida concentrou a repetição de infortúnios, desafios, deficiências e males que trazem sofrimento à juventude brasileira e, ao mesmo tempo, a motivação para suportá-los.

Carregada em sua posição horizontal, por jovens com vestes simples, brancas e cinzas, usando luvas vermelhas, a Cruz estava ornada com uma coroa de espinhos a partir da qual saíam longas fitas nas cores amarelo a branco, que eram seguradas por outros jovens. A cruz só foi suspensa verticalmente ao chegar em frente a cada estação da via crucis, momento em que se descreviam, primeiro os males de Jesus em seu trajeto, depois, cenas referentes a problemas sociais, seguida de meditações sobre as dificuldades de vários grupos sociais brasileiros.

O simbolismo da cruz se reporta facilmente ao da árvore, posto que esta se dirige para cima. É, segundo Durand, o arquétipo da totalidade do mundo, sobretudo se estiver no sentido horizontal, pois mostra a reunião dos contrários ou, quando alçada verticalmente, a união do Yang e do Yin. De acordo com Eliade (2004, p. 184), o simbolismo da Cruz integra os símbolos da Árvore Cósmica e do Centro do Mundo. "A Cruz é descrita como uma 'árvore que sobe da Terra aos Céus', como a 'Árvore de Vida plantada no Calvário', a árvore que 'saindo das profundezas da Terra, se ergueu para o Céu 
e santifica até aos confins do Universo". Assim, ela pode ser considerada "o sinal visível da Redenção efectuada por Jesus Cristo [...]. E como a Redenção se estende a toda a humanidade, a Cruz deveria situar-se no Centro do Mundo, a fim de santificar o Universo inteiro" (ELIADE, 2004, p. 185).

Após a meditação realizada em cada uma das estações e suas exortações dramáticas, os jovens carregavam novamente a Cruz até a próxima estação ao som das matracas e da orquestra sinfônica de Barra Mansa (RJ). Acompanhando este cortejo, um grupo com cerca de 20 coroinhas incensava toda a Avenida Atlântica. A meditação culminou no palco central de Copacabana, onde o Papa e mais 200 jovens receberam a Cruz da Jornada e, juntos com os demais peregrinos, contemplaram o sepultamento de Cristo.

Sabe-se que todo o barulho ou ruído, seja melodioso ou não, constitui a forma de alcançar a percepção do outro, tanto para o bem como para o mal. Neste caso, a matraca pretendeu afastar o Mal e a música desejou aproximar o Bem; incensar, por sua vez, faz parte da mesma estilística: afastar os maus espíritos e espalhar o aroma do bem. Como o incenso é manipulado por coroinhas, recebe também o sentido de pureza da formalidade eclesiástica, sobretudo porque vestem a bata branca sobre uma peça vermelha, conforme determinado pela igreja.

Bem acima do plano do desfile da procissão, sobre a areia, de costas para o mar, via-se o altar que se integrava, também, na estilística da força do divino, como se fosse um produto da natureza, criado para indicar a presença do Senhor nas alturas e, ao mesmo tempo, o poder do homem em tirar proveito dessa mesma natureza. Assim, sobre uma elevação que se alcançava por meio de degraus e de rampa, chegava-se ao espaço do trono, de onde era possível ver 
todo o povo. Atrás do trono havia uma forma retangular, de material aparentemente leve, que descia da parte de trás da cobertura abaulada de vidro, alcançava o piso do trono, depois, em forma de tapete vermelho cobria as escadas e, finalmente, a rampa que chegava até a rua. Sua cor variava conforme a iluminação, indo de vermelho a roxo de acordo com o momento da encenação. Suas linhas verticais formavam um conjunto ascensional impressionante, sinalizando a passagem para um plano superior, compreendido facilmente como o espaço do representante de Deus. Marcou-se assim a diferença de planos: embaixo, o humano; em cima, o divino.

$\mathrm{Na}$ frente dessa estrutura, havia a imagem de uma cruz branca e imponente, que possuía um sentido oposto à da cruz carregada pelos jovens. Se a cruz de madeira simbolizava o sofrimento de Cristo, esta, agora, estava prenhe do simbolismo da ressurreição. Se a primeira, envolta na coroa de espinhos, recordava o suplício e a morte, a segunda, imponente e iluminada com uma luz branca, representava a vitória sobre esta (CHEVALIER; GHEERBRANT, 1988, p. 309-317). Assim, a cruz que estava no palco era, ela mesma, representação do filho de Deus enquanto parte da trindade divina e não mais enquanto homem terreno e pecador.

No piso mais alto, na frente da cruz, destacava-se a imagem única do trono, cujo espaldar branco, alto e circular mostrava-se como uma aureola. Foi lá que se sentou o Papa, só e distante dos dois espaços laterais onde se posicionaram, em um, outros religiosos, sentados, discretos e quietos durante toda a apresentação; em outro, os músicos da Orquestra Sinfônica de Barra Mansa. Acima do trono havia uma cobertura de vidro que tinha o objetivo de proteger da chuva. Ela estava bem alta e sua forma se curvava ao cobrir o cenário do trono. Essas linhas tornaram o espaço mais 
acolhedor, mais leve, mas, ao mesmo tempo, impressionante, porque a faixa de tecido que descia do alto, enquadrava em toda sua largura o trono, dando-lhe o sentido de uma unidade valiosa, mas distante. O papa, sentado só, afastado de todos, traduzia metaforicamente bem a presença de Deus poderoso, solitário, amado e reverenciado, mas longínquo.

Os blocos de jovens e a cruz de madeira ficaram separados do público por meio de cordões ou cercas humanas. Em determinado momentos dividiram o espaço com grupos que se alternavam com diretores de cenas, policiais, um batalhão de oficiais da Marinha perfilados militarmente, grupos de religiosos e os atores que se apresentavam em pequenos quadros que ilustravam as estações da via crucis. Os diretores de cena deram um sentido dramático aos fatos apresentados, sobretudo quando foram utilizadas estátuas vivas em cenas impactantes, prenhes de sentidos religiosos.

A representação nas estações tiveram duas performances distintas, mas sempre com a mesma estilística: provar a possibilidade de vencer o sofrimento mediante a ajuda divina. No plano mais alto, apresentam-se as faces do arquétipo mítico: Jesus Cristo. No plano mais baixo, eram retratadas mensagens que tinham $\mathrm{o}$ intuito de alcançar e fazer compreender os sofrimentos de jovens inocentes, drogados, violentados pela sociedade, homens e mulheres marginalizados, luta contra o aborto, estímulo à fé, à esperança e à religiosidade feminina; testemunhos de fé voltados, em sua maioria, para a metaforização do mal.

Do ponto de vista desses fatos e pensando na interface entre educação e metáfora pela antropologia do imaginário, surgem algumas perspectivas: as metáforas podem ser percebidas, na via crucis, como ferramentas de ensino e aprendizagem de vida, desde 
que pensemos na "estilística" a que se refere Durand, na qual se organizam as imagens, os arquétipos e os mitos.

\section{Considerações finais}

A via crucis representa o sofrimento de Jesus no momento de sua morte e ressurreição. Sua reencenação ritualística reatualiza o mito divino, o acontecimento primordial narrado pelo mito. Segundo Eliade (2004, p. 172), é também nesse momento que os participantes são, progressivamente, introduzidos à presença divina e aos mistérios que ela encerra. Trata-se, portanto, de uma morte iniciática, na medida em que introduz os participantes nos segredos daquela manifestação religiosa.

A morte iniciática é portanto a repetição da morte do Ser sobrenatural, fundador do Mistério. Desde que, durante a iniciação, se repita o drama primordial, reproduz-se também o destino do Ser sobrenatural: a sua morte violenta. Graças à antecipação ritual, a morte é também santificada, carregada de valor religioso (ELIADE, 2004, p. 198).

Assim, reencenar a morte de Cristo é apresentar, ao fiel, o caminho da salvação, da redenção dos pecados e regeneração espiritual, o caminho da imortalidade da alma. Exatamente por isso a via crucis é reatualizada anualmente, por todas as igrejas católicas, durante a Semana Santa.

Reencenar é reatualizar, trazer para a contemporaneidade o sofrimento de Cristo e torná-lo compreensível para aqueles que participam desse fenômeno. Exatamente por isso as meditações da via crucis da Jornada Mundial da Juventude se fazem necessárias. Não basta, 
nesse sentido, reinterpretar os sofrimentos de Cristo, mas também compreender como eles se materializam no mundo atual. A cruz da modernidade não é mais de madeira, mas se constitui a partir das inúmeras injustiças, provações e temeridades que o fiel moderno enfrenta, ou seja, representa o mal do mundo, como apontamos anteriormente. As meditações mostram que sofrimentos menores que os de Jesus podem ser vivenciados por todos, mas que com resiliência e persistência é possível alcançar a divinização da alma.

A metaforização da personagem Jesus em pessoas comuns, mas sofridas, acaba por ser a constatação da existência de uma sociedade brasileira injusta, desassistida e pouco solidária. O lugar em que estavam as estações é marcado por paredes quase sempre incompletas, seja de traves de madeira, tijolos ou blocos de pedra. Todas tinham o número da estação marcado em pedra, confirmando a existência desses vários setores e sua real dramaticidade. Conforme aponta Durand (1989, p. 272), "[a] casa é pois sempre a imagem da intimidade repousante, quer seja templo, palácio ou choupana”.

Nesta jornada, a casa não se restringiu às pessoas, mas a grupos sociais inúmeros e diversificados, pois as meditações não se dirigiam apenas aos jovens, mas, sobretudo, à população desassistida. A grande lição foi a conscientização acerca dessa realidade social e, ao mesmo tempo, a capacidade de, por meio da estilística do imaginário, visualizar um heroísmo confrontado com uma opressão que, mesmo estando difusa em todo o conjunto narrativo, é suficiente para emocionar a plateia e promover um possível e eficaz comprometimento para instaurar a devida assistência social no país.

A presença do cenário noturno, a proximidade da natureza, como o mar ou a areia, pode ter conservado ou criado a intimidade que leva a liberar sensações mobilizadas pelo ruído das ondas do mar, pelas 
conversas a meio tom, pelas aragens da vegetação e do próprio espetáculo do céu de modo a instalar, em cada espectador, o que Durand (1983, p. 235) chama "a intimidade do coração".

A encenação ao vivo da via crucis remete à ideia de sacrifício ao qual foram lançados os mestres e os redentores da humanidade. A redenção se alcança porque se cumpriu um rito: passar pela via do sacrifício para se superar como homem e, assim, tocar no intangível. Via crucis, o caminho do sagrado, representa bem tudo o que constitui o mundo dos homens, submetidos aos antagonismos inerentes à condição humana: oscilar entre o justo e o injusto, o belo e o torpe, o bom e o mau. Experimentar tudo o que é execrável para alcançar o inefável. Essa narrativa aconteceu uma vez para acontecer sempre. O sacrifício pressupõe um mártir, um bode expiatório, destinado a não deixar morrer nos homens a esperança da salvação, que pode ser muito bem resumida na súmula: "eu me sacrifiquei para te salvar". Gandhi, Luther King e Jesus são figuras exemplares desse modelo mítico. Nosso mundo não suporta o sagrado vivo: um homem, quase um Deus.

Marx, Nietzsche e Freud trataram de banir a presença da divindade, mas para eles o divino se circunscrevia ao religioso, uma forma de domesticar os homens, de submetê-los a um conformismo sem escape. O sagrado vai além do religioso: é revolucionário, é educativo, é saneador. Apresenta, aos indivíduos, o caminho que deve ser percorrido, a força que deve ser buscada para se lidar com toda a dor e abnegação necessárias para se transformar num ser iluminado.

Nossa sociedade narcísica e utilitária necessita dessa dimensão do sagrado para se libertar desse paradigma esquizofrênico, norteado pela pressa, pela tecnologia e pelo mercado. A reencenação da via crucis diz muito mais hoje, nestes tempos de angústia existencial, que no tempo histórico do fato verdadeiro e instila, no imaginário das pessoas, a 
possibilidade de reverter uma trajetória que nos foi imposta por uma "mão invisível" que nos obrigou a viver emudecendo as vozes do espírito. Certamente, essa mão não é a mão de Deus. E assim, dessacralizados, "egos inflados", perdemo-nos de nós mesmos, já que a verdadeira humanidade consiste em acatar, acolher, congregar, fraternizar-se com o outro, como se fosse uma pedagogia do sacrifício, a via possível para o alcance do sagrado.

Os ensinamentos da morte iniciática são, portanto, necessários para uma regeneração espiritual, para uma mudança de perspectiva. Ela nos mostra como nos tornarmos um outro, um ser que segue os preceitos revelados por uma divindade antepassada. Ou seja, nos conclama a mudarmos nossas atitudes com o intuito de nos assemelharmos a um Ser sobrenatural.

A sua função é a de revelar às novas gerações o sentido profundo da existência e de as ajudar a assumir a responsabilidade de serem um 'homem verdadeiro' e, por conseguinte, de participarem na cultura. [...] ela revela, em cada nova geração, um mundo aberto para o transhumano, um mundo, diríamos, transcendental" (ELIADE, 2004, p. 199).

\section{Referências}

CHEVALIER, Jean; GHEERBRANT, Alain. Dicionário dos Símbolos. Rio de Janeiro: José Olympio, 1988.

DURAND, Gilbert. A imaginação simbólica, Lisboa: Edições 70, 1993.

DURAND, Gilbert. As estruturas antropológicas do imaginário. Lisboa: Presença, 1989. 
DURAND, Gilbert. Le décor mythique de laChartreuse de Parme. Paris: José Corti, 1983.

ELIADE, Mircea. Ritos de iniciação e sociedades secretas. Lisboa: Ésquilo, 2004.

LAKOFF, G. \& JOHNSON, M. Metáforas da vida cotidiana. São Paulo: Mercado das Letras, 2002.

STRONGOLI, Maria Thereza. Metáfora: encruzilhadas de signos $e$ símbolos. Revista ANPOLL, n. 12, p. 187-215, jan./jun. 2002. 